\title{
Utilization of Web-Based Resources for Medical Research and Education by Health Professionals at the College of Medicine, Ibadan Nigeria \\ By \\ Olorunsaye Joseph Olubunmi
}

\begin{abstract}
A survey was conducted to determine the use of web-based information resources for medical research and education by the health professionals in University College Hospital, Ibadan. Questionnaires were administered to the health professionals in various departments in the Hospital. The results showed a low level of use in spite of high awareness level. This was due inter-alia, to lack of information technology skills, fluctuation of electricity, non-access to useful medical information internet addresses. The study recommends compulsory intensive training for the health professionals. The medical librarian should organize massive awareness workshops on useful medical information websites and constantly circulate.
\end{abstract}

\section{Introduction}

In recent times online information resources are very informative resources. Through this medium, the wealth of information available to man is ever increasing. In the health field, the transportation of multimedia information to various clinical care locations is now possible. Libraries today are more than shelves with books. Increasingly, libraries are providing patrons with access to online resources, such as e-mail, newsgroup, electronic journals, online databases and e-book.

Much progress in online information resources indeed presents a radical challenge to the traditional stronghold of the medical profession, education, practice and research. The development of the Internet, as a vehicle for world wide-wide communication has made instantaneous access to much of the entire body of medical information an exciting one. Gardner, (1997) pointed that doctors need clinical information during most consultations with patients, and much of this need could be satisfied by materials from online sources. Smith, (1996), also opined that information needs arise in nearly every consultation between a doctor and a patient and that many of these needs could be satisfied by material in reference sources, and that improved outcomes might accrue.

Gardner further presented that the supply of information to the point of care relies on four technologies; information sources in digital form, data communication networks, computer devices at the point of care, and information retrieval systems.

There is already a large volume of medically related information available in digital format. This includes abstracts of journal articles (and the full contents of some), full contents of textbooks, clinical trial repositories, care protocols, critical incident reports, libraries of medical images, medical audio libraries (such as characteristic heart sound recordings of hundreds of cardiac disorders), and video clips of medical procedures (such as endoscopy and fibreoptic intubation). In the near future there will be an explosive increase in the volume of information available in digital format.
As in every other revolution, the current Information Technology, or digital revolution, telemedicine, teleconferencing, digital transmissions of every media of information-text, graphics, have completely changed the process of information production, acquisition, storage, retrieval, and dissemination.

The impact of digital technology is evident in the use of electronic information sources such as online library catalogs, biographies, government information on the web., indexes, directories, dictionaries and encyclopedias, and commercial databases. ERIC, e-mail, the World-Wide Web, Wide Area Network, Local Area Network, Newsgroups, online medical databases, and electronic journals, are becoming increasingly available.

Some 1,389 people work in health care in the University College Hospital, Ibadan. They include about 416 physicians, 877 registered nurses, and 15 dentists. Most of them work in health care services, which involve diagnosing and treating patients. Others work mainly in research, teaching, or administration of medical facilities.

In the wake of these information explosion from the web, the health practitioners in Nigeria, whose main primary information sources are print media and interactive sessions with colleagues, are yet to benefit maximally. They need to be in constant touch with new discoveries in the health world and with the wealth of information flow in the global village becomes paramount.

Considering the indispensability of the Internet as a resource, research, reference library and educational tool, there is the pressing need for evaluating web-based information sources use and taking account of the effect of computer basedmedia on medical education and research.

Little is known about the University College Hospital, Ibadan health professionals' awareness and use of the web resources in their work 
environment and the medical library for medical education and research.

Prior to now, the conventional source of medical education and knowledge was the print media. Would the swift shift to web-based information sources enhance the wealth of medical knowledge and research? Would the use of web resources complement the print media or marginalize its use? Considering also the low level of technological advancement and erratic power supply, in the third world countries, would the online resources' use maximally satisfy the information quest of the health professionals vis-à-vis the print media?

\section{Problem Statement}

The paradigm shift from paper-based documentation to web resources implies that medical professionals must move with times to fully explore medical information in the electronic environment. Inability to do so will exclude them from maximal use of information in these frontiers. The web resources are readily available in the medical library but they are underutilized.

Several researchers except in the University College Hospitals have explored the extent to which health science professionals use the online information resources in many countries.

This research is to determine awareness and level of use of web-based information resources for medical research and education by the health professionals in University College Hospital, Ibadan.

\section{Significance of the Study}

The medical librarians as medical information providers should not be left with an unsettling feeling of an elementary level of knowledge as far as it concerns user-needs and information-seeking behavior of Health Professional in College of Medicine and University College Hospital, for medical research and education. Taking into account the constant development in the provision of recent electronic systems or digital collections, the lack of understanding the information seeking behavior poses an obstacle in the process, interpreting the way in which the electronic information services are being delivered.

Critical look therefore becomes pertinent for accurate medical information dissemination to the health professionals and introduce them to more online library resources.

\section{Online Information Resources}

The use of online information resources in today's world is increasing and expectedly varies from one field of knowledge to the other. The online information resource "is an important source of up- to-date medical information" Ajuwon (2003). "It has been used for medical education in diverse ways including teaching of organs, diagnosis of disease and conduct of medical examinations...and as an important source of information for medical research". (Jones et.at 1991, Mansor 2002, Mattheos et.al, 2002, Vitanen, 2002 and Odusanya, 2002).

Walmsley (2003), states that "is an increasingly popular medium for delivering educational material." While Baker et.al (2003), posits, that Online information resources has attracted considerable attention as a means to improve health and health care delivery". Online information resources are becoming increasingly invaluable communications and retrieval tool and means of information provision for those who have discovered it

Banigo (2001) on impact of and use ICT systems posited that: "It is on record that it took 38 years of radio to reach 50 million people and 13 years of television to achieve the same result. Empirical evidence has shown that the same member of people adopted the Internet in just four years. There were 50 pages of the World Wide Web in 1993, but today the pages of the World Wide Web has increased to 1.5 billion with almost two million pages added each day. About 143 million people logged on to the Internet in 1998. In March 2000, an estimated 270 million worldwide were Internet users with a growth rate of 150,000 per day. By the end of the year (i.e. 2001) the number of users will climb to 700 million."

Balen (2004) reported in his finding on online resources use for medical education that, of "Fiftyeight surveys returned within the two-week study period. The survey responses reflected the opinions of licensed B.Sc and hospital pharmacists with a broad range of pharmacy practice experience. Most respondents had home access to personal computers, and regularly used computers in the work environment for drug distribution, information management, and communication purposes.

\section{Medical Education and Research in Nigeria}

Medical education as described by Microsoft Encarta Encyclopaedia (2002) is "a branch of education devoted to training doctors in the practice of medicine". In essence, it is universally directed toward imparting to persons seeking to become physicians the knowledge and skills required for the prevention and treatment of disease. It is also, for developing the methods and objectives appropriate to the study of the still unknown factors that produce disease or favour well-being. While research, is one of the most 
important fields of medicine which provides health care professionals with new knowledge and technology for better diagnosis, treatment, and prevention of disease.

In Nigeria, medical research was noted to have been thriving for the past six decades. According to Adadevoh (1983), it developed initially alongside the development of the colonial health services. Thus, the first institutionalized efforts in medical research were the establishment of research field units and research groups devoted to the solution of health problems through "operation and applied research". During the colonial era local students are trained in University of London, and after the completion of their medical program, they were prepared and screened i.e. house-manship and residency program in Yaba College before the formal professional practice. Thus our medical education has been flourishing, and medical school growing.

However, Nkanginieme (1998), noted that a major setback of medical education in Nigeria as experienced by the health professional was that, there is a complete absence of a functional continuing education programme for all physicians practicing in Nigeria. The pre-occupation is on the international standards and training of the students for international market, at the expense of the local needs and interest.

\section{Online Information Resources and The Medical Profession}

The importance of online information resourcescomputer storage in digital form is numerous to the world of today. The medical professionals and the online information resources are increasingly developing a mutual relationship

In the medical libraries, medical knowledge in print is regularly resorted to by the health professional for needed information. Today, the viewpoint of medical libraries services and importance is gradually changing with the coupling of computer based media to library traditional print services.

\section{Methodology}

There are various groups of health-care professionals in the University College Hospital, which are: medical (doctors) 384; nursing 877; laboratory scientists 61 ; environmental health officers 3; physiotherapists 19; dentists 15 and social workers 13 .

A purposeful quota sampling procedures was adopted to select from the 1372 (Courtesy UCH) broad population of the health professionals. A formal letter was written to the Head of Departments, who assisted in the selection process by stratifying the medical doctors according to ranks, in order to get a reliable and valid data from their categories. While the researcher personally inquired from the departmental secretaries, the exact number of most of the senior officers including the HOD for adequate questionnaire distribution. But in the nursing division, the Senior Nursing Officer (SNO) advised on the need to select the nursing officers alone out of the stream of the nurses since they were the most accessible at the study time.

A detailed structured questionnaire was designed as the instrument for primary data generation. The structured questions provided the respondents with fixed response alternatives that consisted of varying, multiple choices and rating scales.

Interview method was used alongside personal observations to corroborate other sources of information.

\section{Findings \\ Computer literacy of the Respondents}

It was sourced that $80.0 \%$ of the respondents professed to be computer literate while $20.0 \%$ were not. $2.5 \%$ disregarded the enquiry. It is therefore assumed that $22.5 \%$ were computer illiterate. The fact that $20.0 \%$ of the respondents were computer illiterate was serious matter in this technology and information age. It depicted that a large percentage of the health professionals were still being assisted to browse for needed information. The study also found that $31.9 \%$ of the respondents had personal computer in their offices while $68.1 \%$ did not.

The study further showed that $62.7 \%$ of the 61 respondents in all had desktop computer in their offices, while $18.7 \%$ had laptop. It was noted again that $18.7 \%$ of the respondents had both desktop and laptop simultaneously in their offices. Apparently, desktop computer in the offices was the most popular computer used by the health professionals for information processing and communication. However, the low percentage use of laptop by the health profession could be predicated on the high cost of laptop in this part of the world.

\section{Access of respondents to the Internet}

A survey of the access of respondents to the Internet showed that $82.7 \%$ of the respondents had access to the Internet, $17.3 \%$ indicated no access to the Internet, while $4.5 \%$ of the respondents omitted the question.

On searching without assistance in the cybercafe, only $67.8 \%$ of the respondents' searched the computer without assistance while $30.2 \%$ required assistance. However, $8(4.0 \%)$ of the respondents omitted the question. 


\section{Source of Internet Access}

The table showed that $16.8 \%$ of the respondents do accessed the Internet on their personal computer and the ITU (College), while 31.8\% 24.4\%, 5.6\% and $64.0 \%$ accessed the computer in the medical library, ETF cyber café, Information center (UCH) and outside the UCH community respectively. However, it should be noted that the possibility of many of the respondents using more than one of these locations could be impossible, depending on their choice at a particular point in time. For example the Odeku medical library and the ETF are in the same complex. So if one of the locations was congested there could be a spill over to the other unit. Another deduction from the table was that the medical library, in spite of the limited resources is still very much relevant to the users.

Table 1:Sources of Internet Access

\begin{tabular}{|l|l|l|}
\hline Access Locations & $\begin{array}{l}\text { No of } \\
\text { respondents }\end{array}$ & $\%$ \\
\hline Personal Desktop & 33 & 16.8 \\
\hline ITU Unit (College) & 33 & 16.8 \\
\hline Odeku (Library) & 61 & 31.0 \\
\hline ETF Cyber café & 48 & 24.4 \\
\hline Info Center (UCH) & 11 & 5.6 \\
\hline Town & 126 & 64.0 \\
\hline
\end{tabular}

Utilization of the Online Information Resources and Information Retrieval

The utilization pattern of resources showed that $59.9 \%$ of the respondents used the Internet less than one hour per week, $20.4 \%$ for $1-4 \mathrm{hr}$ per week, $12.6 \%$ for $1-2 \mathrm{hrs}$ daily and only $7.2 \%$ for $2 \mathrm{hrs}$ daily. Statistically, It was obvious that majority of the respondents were not using the Internet as expected

Table 2:_Utilization pattern

\begin{tabular}{|l|l|l|}
\hline Regularity & $\begin{array}{l}\text { No of } \\
\text { respondents }\end{array}$ & $\mathbf{\%}$ \\
\hline >2hrs daily & 12 & 7.2 \\
\hline 1-2hrs daily & 21 & 12.6 \\
\hline 1-4hrs. per wk & 34 & 20.4 \\
\hline <than Ihr. per wk & 100 & 59.8 \\
\hline Total & $\mathbf{1 6 7}$ & $\mathbf{1 0 0}$ \\
\hline
\end{tabular}

Online Information Source used for Medical Research and Education

The table showed that out of all the listed online information source, the Informatics electronic mail, $38.9 \%$ was mostly used by the respondents while Archie, Electronic discussion board, the Intranet services, and Campus learning Center (ITU online), were rarely used.

Table 3: Types Online Resources Used : Ratings Key: A=Always, R=Regularly, $\mathbf{O}=$ Occasionally, $\mathbf{N}=\mathrm{Never}$ \begin{tabular}{|l|l}
\hline Types of Internet Services used & Ratings/Respondents
\end{tabular}

\begin{tabular}{|c|c|c|c|c|c|c|c|c|}
\hline & \\
\hline & $\mathbf{A}$ & $\%$ & $\mathbf{R}$ & $\%$ & $\mathbf{O}$ & $\%$ & $\mathbf{N}$ & $\%$ \\
\hline Email. & 68 & 38.9 & 58 & 33.1 & 40 & 22.9 & 9 & 5.1 \\
\hline Newsgroup & 11 & 11.6 & 8 & 8.4 & 18 & 18.9 & 58 & 61.1 \\
\hline Telnet & 5 & 5.6 & - & - & 3 & 3.4 & 81 & 91.0 \\
\hline File Transfer Protocol & 1 & 8 & 3 & 2.3 & 55 & 41.7 & 73 & 55.3 \\
\hline Archie & - & - & 91 & 1.8 & 91 & 54.8 & 72 & 43.4 \\
\hline Gopher & 5 & 3.0 & 5 & 3.0 & 87 & 51.1 & 70 & 41.9 \\
\hline World Wide Web & 24 & 13.5 & 38 & 21.3 & 80 & 44.9 & 36 & 20.2 \\
\hline Access Electronic Journals & 9 & 5.3 & 26 & 15.2 & 96 & 56.1 & 40 & 23.4 \\
\hline Online Lib. Catalogs & 3 & 1.9 & 12 & 7.5 & 116 & 72.0 & 30 & 18.6 \\
\hline Database searches eg. Medline & 8 & 4.5 & 25 & 14.2 & 90 & 51.1 & 53 & 30.1 \\
\hline Coll. Of Med. Intranet sites & - & - & 2 & 1.0 & 129 & 64.5 & 69 & 34.5 \\
\hline $\begin{array}{l}\text { Informatics electronic discussion } \\
\text { board }\end{array}$ & - & - & - & - & 122 & 61.0 & 77 & 38.5 \\
\hline Campus learning center (ITU online) & - & - & 2 & 1.0 & 130 & 65.0 & 68 & 34.0 \\
\hline Electronic books & 5 & 2.5 & 8 & 4.0 & 138 & 69.0 & 49 & 24.5 \\
\hline $\begin{array}{ll}\text { Wide Area } & \text { Information } \\
\text { Serve(WAIS) } & \end{array}$ & 1 & .5 & 4 & 2.0 & 141 & 70.5 & 54 & 27.0 \\
\hline
\end{tabular}




\section{Purpose of Information retrieval}

Depicted that $17.6 \%$ of the respondents used online resources for research, 13.45 for course work, $8.9 \%$ for teaching, $8.9 \%$ for current information; $6.6 \%$ for recreation; $14.5 \%$ for self development; $9.8 \%$ for patient care; $5.2 \%$ for publication, $3.5 \%$ for funds, grants and awards, $3.8 \%$ for conferences/ meetings proceedings and $2.2 \%$ for others; i.e communication and getting messages. It was obvious that the respondents' used the online resources majorly for research work $135(17.6 \%)$, current information 112 (14.6), Self-development 111 (14.5\%) and course work 103 (13.4\%). Statistically therefore, it was noted that the respondents are really using the Internet resources for medical education and research, Except that the electronic information environment had not been fully explored as expected. The level of use was still very low.

Table 4:_Purpose of Information retrieval

\begin{tabular}{|l|l|l|}
\hline $\begin{array}{l}\text { Information retrieval } \\
\text { practices }\end{array}$ & $\begin{array}{l}\text { No of } \\
\text { Respondents }\end{array}$ & $\%$ \\
\hline Research & 135 & 17.6 \\
\hline Course work & 103 & 13.4 \\
\hline Teaching & 68 & 8.9 \\
\hline Current information & 112 & 14.6 \\
\hline Recreation & 51 & 6.6 \\
\hline Self development & 111 & 14.5 \\
\hline Patient Care & 75 & 9,8 \\
\hline Publication & 40 & 5.2 \\
\hline $\begin{array}{l}\text { Funding, grants and } \\
\text { awards }\end{array}$ & 27 & 3.5 \\
\hline $\begin{array}{l}\text { Conferences/Meeting } \\
\text { s, Proceedings }\end{array}$ & 29 & 3.8 \\
\hline Others & 17 & 2.2 \\
\hline
\end{tabular}

\section{Expected benefits from the online information resources}

The findings depicted that expected benefits from online information resources really influenced the health professional quest for information. 173 $(35.8 \%)$ of the respondents were better informed, $7.5 \%$ for desktop access, $19.5 \%$ for only way to some information, $18.6 \%$ for better contact to colleagues, $18.6 \%$ for diagnosis and therapy update.

Evidently, the desires of the respondents though vary, yet influenced the quest for better education.
Table 5: Expected benefits of the online information resources

\begin{tabular}{|l|l|l|}
\hline Internet Benefit & $\begin{array}{l}\text { No of } \\
\text { respondents }\end{array}$ & $\%$ \\
\hline Better Informed & 173 & $\begin{array}{l}35 . \\
8\end{array}$ \\
\hline Desktop access & 36 & 7.5 \\
\hline $\begin{array}{l}\text { Only way to some } \\
\text { Info }\end{array}$ & 94 & $\begin{array}{l}19 . \\
5\end{array}$ \\
\hline $\begin{array}{l}\text { Better contact with } \\
\text { colleagues }\end{array}$ & 90 & $\begin{array}{l}18 . \\
6\end{array}$ \\
\hline $\begin{array}{l}\text { Diagnosis \& } \\
\text { Therapy update }\end{array}$ & 90 & $\begin{array}{l}18 . \\
6\end{array}$ \\
\hline Others & Nil & Nil \\
\hline
\end{tabular}

\section{Search Engines Used}

Determining the search engines used, $80 \%$ of the respondents claimed the use of goggle most often, while 58.2\% used Yahoo, 6\% Lycos, MSN 9.4\% while those who specify the use of other search engines was $1.8 \%$ Statistically out of the 200 respondents, it was obvious that those who claimed the use of goggle seem to be the highest.

Table $8 \quad$ Search engines used

\begin{tabular}{|l|l|l|}
\hline $\begin{array}{l}\text { Search } \\
\text { engines used }\end{array}$ & $\begin{array}{l}\text { No of } \\
\text { respondents }\end{array}$ & \% \\
\hline Goggle & 136 & 80.0 \\
\hline Yahoo & 99 & 58.2 \\
\hline Lycos & 1 & .6 \\
\hline MSN & 16 & 9.4 \\
\hline Pubmed & 3 & 1.8 \\
\hline Others & 3 & 1.8 \\
\hline
\end{tabular}

Relevance or importance attached Accessed Online Information

Depicted that $71.8 \%$ of the respondents claimed that the online information resource were very important to their subject and teaching needs while $24.9 \%$ claimed it as relevant, and $3.4 \%$ not relevant only $16.5 \%$ omitted the question. It was obvious overall that about $96.6 \%$ of the respondents claimed the relevance of online information resources to their subject and teaching needs.

The importance attached to online information resources used in relation to curriculum, teaching method, medical education and research can be seen overall, in that none of the respondent rated the print media above the e-media resources but above average on medical education. 


\section{Summary of findings}

Provision of accurate and timely information is one of the indisputable roles of the librarians. In the digital age, the electronic machine as a tool is making the role much the more efficient. With this tool, the world is gradually becoming a global village where information can be accessible to all. This ever-increasing role of the librarian prompted the need to investigate the use of web-based information sources for medical research and education by the health professionals for better performance and efficient information service

The statistical analysis showed that the UCH health professionals were developing a keen interest in the use of electronic resources as a means to an end on medical education and research. The pattern of use of the online information resources is actually transforming medical education and research except that impact is not yet felt in their professional practices.

However, it was noted that the respondents were well aware of using the Internet resources for medical education and research. But the level of use is still very low. The ranges of online information resources used currently by the health professional are also limited and narrow to individual skill.

The different practices and methods used by health professionals in retrieving information from electronic information sources vary widely. It was noted that the importance of electronic information use on curriculum development and teaching methods in medical education and research is very rare. Apparently, the quest of the health professional is far from being satisfied due to the low level of various useful addresses of information locations. The health professionals valued immensely the information available online and rated it very high for research, teaching, professional practice and for medical education.

Finally, the ratings of the respondents on e-media on curriculum development research, medical education and professional practice, overshoot that of the print media except on certain areas such as curriculum development.

\section{Implication of Findings}

The implication of these is that most of the online information resources that were of good use to the health professional were occasionally used. The reason for this as depicted by the respondents includes:

a). Fluctuation of electricity.

b). Slow speed of Internet connection.

c). Restrictions and non-availability of cited references in full text.

\section{d). Computer illiteracy}

\section{Conclusion}

It is obvious that the online information resources and services are becoming prominent in the drive for making information and data available to the health professionals especially on medical education and research in the developing countries. The study revealed that in spite of the prominence of the Internet resources and cyber café within the University College Hospital the assumption that many of the health professional are making judicious use of the online resources was discovered to be untrue. The expected landmark is far from being reached. This emerging technology must be well tapped to advance the health for all initiatives.

\section{Recommendation}

The disadvantages of the Internet resources use throw a great challenge to the health professionals' librarians to find a lasting to solution to problems. The tidal waves of exchange sweeping through the whole world must not be denied the health professionals in the University College Hospital. The situation therefore demands:

a) The provision of uninterrupted power supply which will doubtlessly enhance the constant patrons' use of the library and justify the establishment and funding of the library by the management and the community it serves.

b) Compulsory enlightenment programmes on online information resources and their URLs for the health professionals, computer literacy seminars and workshops, which would be a necessary bait and source of revenue that should be explored for the promotion of online resources constant use and awareness.

c) Operating a twenty-four hours online information service for maximum effective use of the online resources by the health professionals is a matter of urgent consideration. This will be a good means of revenue generation.

d) The need to resort to International consortium or cooperative medical librarianship as an alternative measure shortage of fund

e) There is the need to make more internet facilities available to the library clientele.

\section{References}

Adadevoh, B.K. (1983) Medical Research in Nigeria: A tribute with historical and perspective considerations. Educational Professional and Scientific Publications, Lagos, 93p.

Ajuwon, G.A. (2003) Computer and Internet use by first year clinical and nursing students in a Nigerian teaching hospital. British Medical 
Companion Medical Informatics and Decision Making 3:10

Alegbeleye, G.O. (1989) Studies on users information needs: a critique and suggestions. In: Nigerian Library and Information Science Review. Journal of Oyo State Division of Nigeria library Association. 7 (2):1-8.

Bird, G. and Heekin, J.M (1994) Survey on the use of information sources in the field of aging Bulletin of Medical Library Association 82 (1):30-35.

Carney P.A., Poor, D.A., Schifferdecker, K.E., Gephart, D.S., Brooks, W.B., \& Nierenberg, D.W. (2004). Computer use among community-based primary care physician preceptors. Academic Medicine.2000 Jun;79(6):580-90.

Coiera E. (2000). Information Economics and the internet. Journal of American Medical Information Association. 2000 May; 7(3): 215221.

http://www.pubmedcentral.gov/articlerender.fc gi?tool=pmcentrez\&artid $=61423$ accessed on 10.01.2005

Dietrick, I.E. \& Berson, R.C. Medical Schools in United States at Mid-Century.McGraw-Hill Book Company, Inc., New York 1953; 380p

Eberhart-Phillips J, Hall K, Herbison GP, Jenkins S, Lambert J, Ng R, Nicholson M, Rankin L. (2000). Internet use amongst New Zealand general practitioners. New Zealand Medical Journal 2000 Apr; 113(1108):135-7 [PubMed]

Encyclopedia Britannica (2003). Macropaedia Knowledge in Depth Volume 23 Chicago: Encyclopedia Britannica, Inc. 2003; 1018p.

Gardner, M. (1997) Information retrieval for patient care. British Medical Journal. 1997 Mar 29;314(7085):950-3.

Grefsheim S, Franklin J, Cunningham D. (1991) Biotechnology awareness study, part I: Where scientists get their information. Bulletin of Medical Library Association 1991 Jan;79(1):36-44.

Gruppen LD. (1990) Physician information seeking: improving relevance through research. Bulletin Medical Library Association Apr; 78(2):165-72.

Harrod, L.M. (1995) Harrod's librarian glossary. $8^{\text {th }}$ edition Harrods 692p.

HEALTH ON THE NET FOUNDATION. Survey August/Sept 97-results. [Web document] Geneva: Health On the Net Foundation, 1997. [rev. 12 Feb 1998; cited 30 Apr 1998]. Available from Internet: (http://www.hon.ch/ cgi-bin/ quest/ quesLnetSep).

Henderson T, Macewan B.(1997) Electronic collections and wired faculty. Library Trends 1997 Winter;45(3):488-98.

Hektor, A.(2001). What's the use? Internet and information behaviour in everyday life.
Linköping: Linkoping University, Tema. 2001. 338

p. http://www.bibl.liu.se/liupubl/disp/disp2001/ar ts240s.htm

Humphreys BL.(2000) Electronic Health Record Meets Digital Library: A New Environment for Achieving an Old Goal Journal of the American Medical Informatics Association 7( 5): 444-452.

Ikem J.I. (2000) A historical and evaluative study of the Ibadan University library system and a projection into its future development. Unpublished paper. 34pp.

Jeddah. J Ayub Med Coll (2002). Computer skills among medical students: a survey at the King Abdul Aziz University, Jeddah. Journal of Ayub Medical College 2002, 14(3):13-15

Jones RB, Navin LM, Barrie J, Hillan E, Kinane D (1991). Computer literacy among, medical, nursing, dental and veterinary undergraduates. Medical Education 1991, 25:191-195.

Kathy Ennis (1995) Guidelines for college libraries: recommendation for performance and resourcing. $5^{\text {th }}$ edition, London: London Library Association published.

Kiley R. (1999) Medical Information on the Internet: a guide for health Professionals. 2ed Edingburgh: ChurchHill Livingstone. 1999; $160 \mathrm{p}$ http://www.dlib.org/dlib/october02/montgomer y/10montgomery.html. Accessed on October 20,2004.

Koller M, Grutter R, Peltenburg M, Fischer JE, Steurer J.(2001) Use of the Internet by medical doctors in Switzerland. Swiss Medical Weekly 2001 May 5; 131(17-18):251-4

Lacher, D., Nelson, E., Bylsma, W., Spena R. (2000). Computer use and needs of internists: a survey of members of the American College of Physicians-American Society of Internal Medicine. Procteria-America Medical International Association Symposia. 2000;:453-6.

Limberg, L. (1999). "Experiencing information seeking and learning: a study of the interaction between two phenomena." Information Research.1999; 5(1) Available at: http://informationr.net/ir/5-1/paper68.html accessed on 26/07/2004.

Lowe HJ. (1999) Multimedia electronic medical record systems.Academic Mediciine. 74(2):146-52.

Mansor I (2002). Computer skills among medical students: a survey at the King Abdul Aziz University, Jeddah. Journal Ayub Medical College 2002, 14(3):13-15.

Mandhan P. (1998) Introducing the Internet to medical practitioners. Journal of Pakistan Medical Association. 1998 Jul;48(7):214-8. 
http://www.ncbi.nlm.nih.gov/entrez/query.fcgi?cm $\underline{\mathrm{d}=\text { Retrieve } \& \mathrm{db}=\text { pubmed } \& \mathrm{dopt}=\text { Abstract } \& \text { list }}$ uids $=10067028$

Martins S. (2003). MDs' office Internet use hits $57 \%$.

Canadian Medical Association Journal. 2003 Feb 18;168(4):475.

http://www.ncbi.nlm.nih.gov/entrez/query.fcgi?cm $\mathrm{d}=$ retrieve \&db=pubmed\&list_uids $=12591809$ accessed on 13.01.2005

Mattheos N, Nattestad A, Schittek M, Attstrom R.(2002). Computer literacy and attitudes among students in 16 European dental schools: current aspects, regional differences and future trends. European Journal of Dental Education 2002, 6(1):30-35

Microsoft Encarta Encyclopedia (2002). 1993-2001 Microsoft Corporation.

Morris, A.(1999) Experimental evaluation of selected electronics document delivery systems. In: Journal of librarianship and Information Science, 31 (3): 135 -144.

Obst. O. (1998). Use of Internet resources by German medical professionals. Bulletin of Medical Librarian Association October; 86(4): 528-533.

http://www.pubmedcentral.nih.gov/articlerend er.fcgi?tool=pubmed \&pubmedid=9803296. accessed on 13.01.2005

Odusanya, O.O.\& Bamgbala, O.(2002). Computing and information technology skills of final year medical and dental students at the College of Medicine, University of Lagos, Nigeria. Nigeria Postgraduate Medical Journal 2002, 9(4):189-193.

Olorunsaye, J.O. (2000). Evaluation of resources and services of E Latunde Odeku Medical Library. Unpublished BLIS degree Thesis submitted to Centre for External Degree University of Ibadan, Ibadan.

Pelzer Nl, Leysen JM. (1991) Use of information resources by veterinary practitioners. Bulletin Medical Library Association Jan;79(1):10-6.

Pitkala, K.H.\& Mantyranta, T. (2003). Professional socialization revised: Medical students' own conceptions related to adoption of the future physician's role-a qualitative study. Medical Teacher 2003;25: 155-60.

Radcliffe, C.\& Lester, H.(2003) Perceived stress during undergraduate medical training: a qualitative study. Medical Education 2003;37: 32-8.

Renwick S.(2005)Knowledge and use of online information resources by medical sciences faculty at The University of the West Indies. Journal of Medical Library Association. 2005 Jan; 93(1): 21-31.

Schement R. J. (1996) A 21st-century strategy for librarians. Library Journal May 1;121(8):3436.
Shumway JM, Jachnowitz AI, Abate MA. (1990) Analysis of physicians', pharmacists' and nurses' attitudes toward the use of computers to access drug information. Methods Informatics on Medicine Mar;29 (2):99-103

Siatri, R. (1998) Information seeking in electronic environment: a comparative investigation among computer scientists in British and Greek universities. http://InformationR.net /ir/4/isic/siatri.html Accessed on October 20,2004

Smith R. (1996). What clinical information do doctors need? British Medical Journal 1996; 313:1062-8.

University College Hospital Hand Diary 2002.

Verhoeven A.A.H., Boerma E.J, Meyboom-de Jong B. (1995) Use of information sources by family physicians: a literature survey. Bulletin Medical Librarian Association 1995 Jan; 83(1):85-90.

http://www.pubmedcentral.gov/articlerender.fc gi?artid=226003 accessed on 13.01.2005

Virtanen, J.I. \& Nieminen, P. (2002). Information and communication technology among undergraduate dental students in Finland. European Journal Dental Education 2002, 6(1):147-152.

Walmsley, A. D., White, D. A., Eynon, R. \& Somerfield, L.(2003) The use of the Internet within a dental school. European Journal of Dental

Education 7 (1), 27-33. doi: 10.1034/

Waldman, M. (2003) "Freshmen's use of library electronic resources and selfefficacy"Information Research, 8(2), paper no. 150 [Available at: http://informationr.net/ir/82/paper150.html].

Wkyatt J. (1991). The use and sources of medical knowledge. The Lancet 1991;338:1368-1373.

Willinger, W. et.al (2002). Scaling phenomena in the Internet: Critically examining criticality. Pretoria National Academic Science U.S.A. February;99(Suppl.1)2573-2580

http://www.pubmedcentral.gov/tocrender.fcgi? action $=$ cited\&artid $=128578$. accessed on 10.10.2005.

Wood F.B, Wallingford KT, Siegel ER. (1997) Transitioning to the Internet: results of a National Library of Medicine user survey. Bulletin Medical Librarian Association Oct; $85(4): 331-40$.

Wozar,J.A. \& Paul C. Worona, P.C. (2003) The use of online information resources by nurses. Journal of Medical Librarian Association. 2003 April; 91(2): 216-221. 